\title{
Pedro Rodríguez de Campomanes y el discurso sobre la educación popular
}

\author{
Antonio E. de Pedro Robles \\ Universidad Autónoma de Tamaulipas (México)
}

CES.XVIII, núm. 17 (2007), págs. 275-298. 
Resumen: Este trabajo se propone analizar algunos aspectos sobresalientes del ideario educativo de Pedro Rodríguez, conde de Campomanes, vertidos en una de sus principales obras, el Discurso sobre la educación popular de los artesanos y su fomento. En este sentido, nuestra lectura del texto parte desde dos posicionamientos: el primero reconoce la obra como una de las más significativas de la Ilustración española respecto a los criterios educativos a aplicar para el fomento y la dignidad social del estamento popular, aunado al hecho de concebir la enseñanza de las clases populares como un factor de enriquecimiento económico y de progreso social; y el segundo, concibe este fomento de la educación popular como un proyecto desarrollado desde un posicionamiento ideológico de continuidad reformista y no de ruptura con el pasado y sus tradiciones.

El pensamiento educativo de Campomanes ni ha sido tan pragmático como se le supone, ni tampoco inaugura, de manera explícita, las bases del liberalismo educativo. Por el contrario, sostenemos que sus ideas y propuestas son tan sólo el reflejo de unos planteamientos que navegan entre un pragmatismo utópico (si algo tan contradictorio en sí mismo puede existir) y un conservadurismo social, que se reviste de «modernidad» y «puesta al día». Campomanes es un ilustrado a la «manera española». Contemplador de la «paz y la felicidad social» desde la tribuna privilegiada del poder monárquico. Combativo del clero romano, sin llegar a ser anticlerical; apasionado por el progreso de las artes y de la industria, sin abandonar su tradicionalismo de utopía agrario pastoral (Pablo F. LUNA, «El intocable dominio y las reformas de la posesión: Los planteamientos de Campomanes», en Tiempos Modernos. Revista Electrónica de Historia Moderna, Barcelona, 2005, núm. 12, vol. 2, pág. 8, 〈www.tiemposmodernos.org〉.); y voluntarista entusiasmado de las nuevas ideas educativas, sin que su aplicación supusiese la socavación y el fin de la moralidad católica, que se seguía manteniendo como eje estructurador de la sociedad española (la Ilustración española no se puede observar como un grupo ideológico homogéneo, sino más bien como una «elite cultural y política» que comparte una manera de ver y diagnosticar los problemas que afectan a España y su imperio. Pero que, no obstante, poseen diferencias sustanciales a la hora de enfrentar y de establecer las medidas necesarias para su solución y regeneración. En este sentido, no es lo mismo el accionar ilustrado del conde de Floriblanca que el de Campomanes o el del mismo Jovellanos, con quien Campomanes compartió ideales y proyectos. En síntesis, el movimiento ilustrado español se caracterizó por esa heterogeneidad de acción, yendo desde posiciones y propuestas que pueden ser calificadas de progresistas, hasta posiciones evidentemente conservadoras).

Campomanes era un hombre de una enorme erudición, de un profundo conocimiento de la historia española y de una cierta originalidad burocrática que le permitió ofrecer al poder despótico de la monarquía, las «recetas» necesarias para ajustar, moldear o, en todo caso, cambiar, lo imprescindible. Pero su accionar y su pensamiento jamás abandonaron el marco de la «legalidad controlada». Una legalidad que, aun a sabiendas de que era insuficiente, resultaba difícil de manejar y proteger frente a los continuos ataques sufridos desde los púlpitos y los rancios salones de la aristocracia transmontana.

Palabras clave: Campomanes. Educación. 
En 1774, Campomanes publicó su Discurso sobre el fomento de la industria popular. Un año después, en 1775, apareció Discurso sobre la educación popular de los artesanos y su fomento ${ }^{1}$. En ambas obras quedaban plasmadas sus ideas en relación con el progreso, la educación y las artes ${ }^{2}$.

La primera de estas obras, distribuida a todos los funcionarios e instituciones del gobierno español incluyendo los obispados, se convirtió, con el tiempo, en un referente fundamental del ideario ilustrado español; un proyecto político, social y económico que Sarrailh denominó como: «culture utilitaire et culture dirigée». Su propósito, a todas luces, resultaba evidente: «desterrar la ociosidad y promover la industria popular y común de las gentes» ${ }^{3}$.

La segunda obra, que puede entenderse como complementaria de la primera, pone un mayor énfasis en los aspectos relativos a la educación popular ${ }^{4}$. En este sentido, Campomanes entiende por «popular», lo que ya por entonces era común a la Europa ilustrada y que estaba en consonancia con lo que Jaucourt había planteado en la Enciclopedia: «No quedan, pues, en la masa del pueblo, más que los obreros y los labradores» ${ }^{5}$. En este sentido, en el primer apartado del Discurso sobre la educación popular, denominado: «Objeto de este discurso», Campomanes afirma taxativamente: "La educación es la norma de vivir las gentes, constituidas en cualquier sociedad, bien ordenada» 6 .

$1 \quad$ Hemos manejado para este estudio la edición digital que se ha hecho a partir de la edición de 1775 publicada por la Imprenta de Antonio Sancha y cotejada con la edición crítica de John Reeder editada en Madrid por el Ministerio de Hacienda en 1975.

2 Marcelino Menéndez Pelayo afirma que tanto esta obra, como la que es motivo de nuestro análisis, fueron «impuestas» por Campomanes como libros de obligada lectura en la Iglesia: «como libros sagrados, al modo que los liberales de Cádiz lo hicieron con la Constitución». No obstante, ya sabemos lo dado que es a exagerar don Marcelino cuando se trata de hablar de los ilustrados españoles. Personajes que despertaban pocas simpatías al filólogo e historiador cántabro (Marcelino Menéndez Pelayo, Historia de los heterodoxos españoles. Regalismo y Enciclopedia, 1983, México, Editorial Porrúa, pág. 90).

3 Ibid., pág. 1, nota 4.

4 Los planteamientos educativos de esta obra, están íntimamente ligados al proyecto de la creación de la Sociedades Económicas de Amigos del País desarrollado por Campomanes en su anterior Discurso sobre la industria popular. Es allí, en el seno de estas Sociedades Económicas, donde los preceptos educativos encuentran plena instrumentación práctica.

5 Jaucourt, «Pueblo», en La Enciclopedia, Barcelona, Crítica, 1988, s. v., pág. 164.

6 Pablo F. Luna, op. cit., pág. 1, nota 5. 
Si en la primera de las obras mencionadas se atendía de manera papable y evidente al fomento de las artes y la industria (antecedentes, acciones, medidas, características y peculiaridades), en esta se establecen las bases educativas para alcanzar los objetivos anteriores; desde un visionar exclusivamente práctico, pero justificado por un discurso teórico que tiene mucho de erudición histórica y bibliográfica ${ }^{7}$.

A nuestro modo de ver, tres son los conceptos vertebradores de esta obra. El primero, establece una educación en función de una estructura social asentada en la tradición de la monarquía absolutista. Una monarquía que se veía forzada a superar los viejos criterios degradantes en relación con las artes y los oficios desarrollados por el pueblo. Actividades manuales que habían sido calificadas tradicionalmente como actividades alejadas de cualquier impronta intelectual. La gran apuesta de Campomanes era la de tratar de superar este escenario, dotando a la enseñanza de las artes y oficios de un nuevo marco social y cultural de legitimidad; e incidiendo en la beneficiosa y necesaria enseñanza del dibujo, de la lectura, de la escritura y de ciertos conocimientos matemáticos. Además, procurar a las mujeres campesinas una educación que tenía la finalidad de convertirlas en un instrumento útil a la sociedad, tratando de desterrar del imaginario colectivo, ciertas prácticas ociosas que en nada habían contribuido al progreso económico.

En segundo lugar, Campomanes se plantea una educación eminentemente técnica. Una educación que es, a su vez, una instrucción moral, asentada en la «modernización» de determinados valores tradicionales de identidad colectiva.

Por último, nuestro autor concibe la educación como un «bien público», capaz de generar la «paz social» y obtener así la «felicidad de la nación». Todo ello bajo el reforzamiento del prioritario papel del Estado como regulador y controlador de la sociedad civil.

Cada una de estas tres concepciones quedan interconectadas y ejemplificadas en la lectura que el pensador ilustrado realiza de la sociedad de su tiempo: de sus carencias y virtudes, de sus referentes morales y religiosos, de sus usos y costumbres.

En fin, todo un proyecto educativo, social, cultural, moral y, sobre todo, económico, que pretende transformar la sociedad española, privilegiando el sentir

7 Es de todos sabido la cultura enciclopédica que poseía Campomanes y la diversidad de temas de su interés: desde la historia, pasando por la política y la economía, hasta la medicina, la botánica o los tratados sobre arte; sin descartar, la literatura clásica y moderna y sus traducciones del griego e incluso del árabe. Su biblioteca constaba de cerca de cinco mil volúmenes, establecidos en varias temáticas o secciones: religión, derecho, historia, ciencias y artes, y bellas artes (vid. Jacques SoubEYRoux, «La biblioteca de Campomanes: contexto cultural de un ilustrado», en AIH. Actas VII, Madrid, Instituto Cultural Cervantes, 1980, págs. 997-1006. 
básico de la organización monárquica como un cuerpo, en el que cada uno de sus miembros asuma con eficacia sus funciones y obligaciones; ofertándosele para ello, los instrumentos más idóneos y necesarios.

Campomanes parte del concepto de que la educación es «diferente y respectiva a las clases de la misma sociedad ${ }^{8}$. Lo que significa que en una sociedad estratificada como la española, no todos los estamentos que la componen requieren del mismo tipo de educación; ni todos tampoco deben aspirar a una misma educación; aunque todos deben recibir algún tipo de educación. En este sentir, Campomanes coincide con Beccaria, el pensador jesuita italiano, en que: «El hombre ilustrado es el don más precioso que puede hacer la nación y a sí mismo el soberano, que lo hace depositario y custodio de las santas leyes» ${ }^{9}$. Es bajo estos preceptos que el calificativo de «popular» adquiere, en el proyecto del pensador asturiano, plena justificación. Una enseñanza popular estará entonces destinada a un determinado sector social que no puede ser otro que las clases productivas. Y como tal, es, ante todo, una enseñanza particular, no generalizada al resto del cuerpo social: «Tienen necesidad los cuerpos de oficios, o gremios de artesanos, de una educación y enseñanza particular; respectiva a cada arte, al porte correspondiente al oficio, que ejercen» ${ }^{10}$.

Ahora bien. Siguiendo con el argumento anterior, nos surgen algunas preguntas a las que trataremos de responder a lo largo del desarrollo de este texto: ¿De qué tipo de educación se esta hablando? ¿Es esta una educación que por el hecho de llevar el calificativo de "popular» implica algún tipo de significación especial? Y, en todo caso: ¿Qué encierra esta clasificación de «educación popular» en relación con otro tipo de educación que se impartía en la sociedad española del momento?

La primera pista al respecto de ir despegando interrogantes, la tenemos en la parte introductoria de esta misma obra de Campomanes, cuando se afirma: «Esta educación técnica, y moral suele ser defectuosa, y descuidada entre nuestros artesanos: persuadiéndose no pocos, de que un menestral no necesita educación popular» ${ }^{11}$.

8 Pedro Rodríguez de Campomanes (1775), Discurso sobre la educación popular de los artesanos y su fomento, edición digital a partir de la edición de Madrid, Imprenta de Antonio Sancha de 1775, y cotejada con la edición crítica de John Reeder, Madrid, Ministerio de Hacienda, 1975, pág. 1.

9 Cesare Beccaria (1984), De los delitos y las penas, Barcelona, Urbis, pág. 114.

10 Pedro Rodríguez de Campomanes, op. cit., pág. 1.

11 Id. (cursivas nuestras). 
Efectivamente, la educación popular aparece ya definida como una educación «técnica y moral». Al respecto, Campomanes realiza una distinción —apoyada en una reflexión teórica e histórica- entre las Ciencias y las Artes. Define las primeras, como ciencias que «dependen del ánima» y son «meramente especulativas», requiriendo para su estudio de una combinación ordenada y progresiva de ideas ${ }^{12}$. Y a propósito añade: «proporcionalmente las ciencias humanas deben apoyarse en las demostraciones, que suministran un buen raciocinio, y el orden geométrico de comparar las ideas ${ }^{13}$. Dentro de este grupo se encontrarían ciencias especulativas como la matemática, que es una ciencia que «inmediatamente influye en las artes prácticas, $u$ oficios de que se va a tratar en este discurso» ${ }^{14}$.

Por el contrario, en relación con las Artes, Campomanes señala: «La voz artes, comprende las ciencias especulativas, y a todos los oficios prácticos, que constan de reglas, porque unos y otros conocimientos necesitan ayudarse del artificio de ellas y de las demostraciones: más o menos» ${ }^{15}$. Y, más adelante afirma: «Por artes sólo entiendo a las que necesitan de reglas y aprendizaje» ${ }^{16}$.

Como se puede observar, las artes conllevan para Campomanes una utilidad práctica que aparentemente no está presente, por sí mismas, en las llamadas «ciencias especulativas». Las artes no sólo tienen esa vocación utilitaria sino que se valen de las ciencias especulativas, caso de la matemática (más adelante mencionará al dibujo como un instrumento situado a caballo entre lo especulativo y lo práctico), para conseguir estos fines ${ }^{17}$.

Pero hay otro aspecto de los planteamientos del conde que no quiero dejar pasar por alto. Se refiere en concreto al hecho de que hay ciertas artes que han quedado asociadas a los oficios prácticos. En este sentido, los oficios prácticos son aquellos que se distinguen del «sustento ordinario de los hombres» ${ }^{18} \mathrm{y}$ que «por lo común requieren arte y regla». De manera que esta equiparación de determinados oficios con ciertas artes es lo que le permite a nuestro autor ofrecer un argumento verosímil con el que facilitar el quiebre del tradicional estatus de

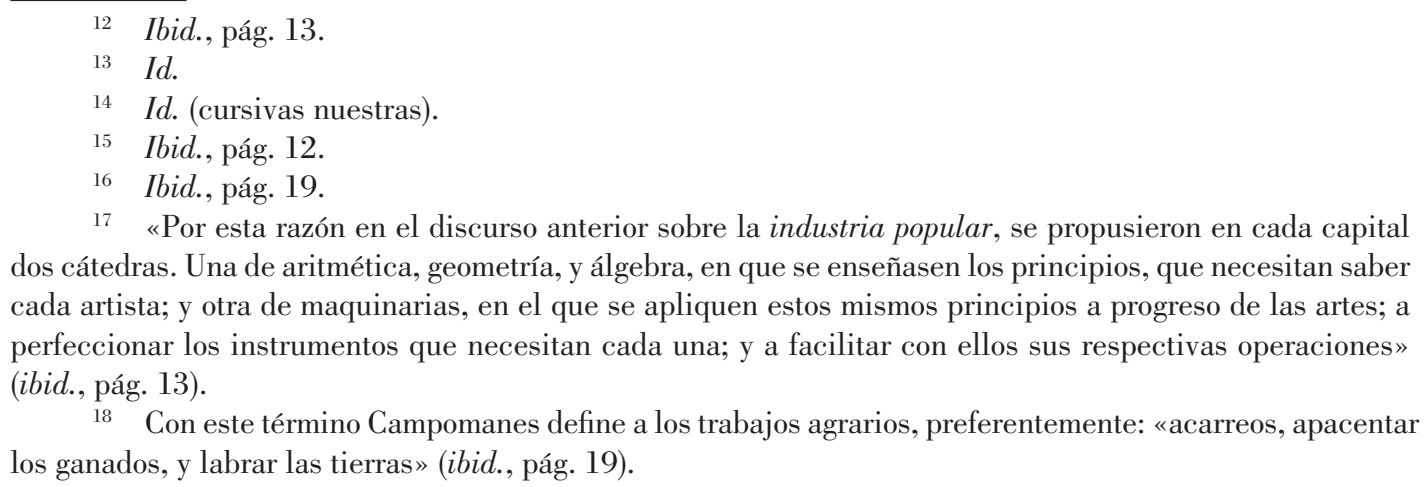
dos cátedras. Una de aritmética, geometría, y álgebra, en que se enseñasen los principios, que necesitan saber cada artista; y otra de maquinarias, en el que se apliquen estos mismos principios a progreso de las artes; a perfeccionar los instrumentos que necesitan cada una; y a facilitar con ellos sus respectivas operaciones»

18 Con este término Campomanes define a los trabajos agrarios, preferentemente: «acarreos, apacentar los ganados, y labrar las tierras» (ibid., pág. 19). (ibid., pág. 13). 
inferioridad social de las actividades manuales. Es decir, dejar de ser vistas estas actividades como prácticas esencialmente «rudas» e «innobles»:

Los oficios y las artes que no son puramente ministeriales, no sólo requieren la fatiga corporal: es necesario saber las reglas del arte, conocer y manejar los instrumentos, que son propios a cada una de sus maniobras, discerniendo distintamente su uso y el de los materiales, que entran en las composiciones de él ${ }^{19}$.

Hecha esta asociación, la historia de los oficios, según las apreciaciones de Campomanes, formaría parte de la misma historia de las artes. Es decir, lo que se habría producido a lo largo de la historia de las artes manuales es una lucha por conquistar un nuevo nivel de conocimiento, una nueva legitimidad social que les permitiese «alejarse» desde aquellos tempranos inicios que se habían caracterizado por la «rudeza de experiencias y observaciones»; hasta convertirse, ya en tiempos de la Ilustración, en actividades guiadas por «reglas» (más o menos complejas, según el caso de cada oficio) que ameritaban de un aprendizaje y de una enseñanza especializada: «El intento de este discurso - afirma Campomanes - se encamina a sacarlos de su decadencia. Eso no es fácil de lograr, sin esfuerzos de su parte: ayudados de la sabiduría del Gobierno» ${ }^{20}$.

A esta nueva equiparación racionalista de los oficios, habría contribuido sin duda, la enseñanza y práctica del dibujo. De hecho, es el dibujo quien mejor y mayormente propicia ese nuevos estatus. De la mano de algunos tratadistas europeos, exaltadores de las virtudes intelectuales del estudio del dibujo ${ }^{21}$, el ilustrado español convierte su enseñanza en instrumento fundamental de las artes manuales. Así, el dibujo es una necesidad que permitirá recobrar a «los oficios su esplendor ${ }^{22}$. De manera que su enseñanza debe ser materia obligatoria del nuevo aprendizaje artesano. Incluso plantea que su conocimiento debe ampliarse a otros sectores populares como los «mancebos de los mercaderes»,

\footnotetext{
19 Ibid., pág. 15.

$20 \quad$ Ibid., pág. 35.

21 Campomanes se muestra en este apartado como un hombre de una basta cultura artística. Sus citas de los tratadistas son certeras y ajustadas. Su defensa del arte del dibujo, debe ser entendida, más bien, como defensa del dibujo como disegno, atendiendo que ambas voces son empleadas indistintamente por el asturiano. El disegno adquiere en el siglo XVIII una significación más amplia, ligada a la invención humana; a un tipo determinado de «conocimiento práctico» que supera la pura concepción manual. Que, por otra parte, no era nueva y tenía antecedentes precisamente en muchos de los autores citados por Campomanes. Concepción que se remontaba a las viejas disputas estéticas europeas entre aristotélicos y neoplatónicos en razón de la imagen resultado de su instrumentación: imagen como reflejo, o imagen como idea (vid. Steplana AlPERs, El arte de describir. El arte holandés en el siglo XVII. Madrid, Hermann Brumen, 1987).

22 Pedro Rodríguez de Campomanes, Discurso sobre la educación popular, op. cit., pág. 22.
} 
para que estos sepan distinguir «los géneros en que comercian» ${ }^{23}$. En definitiva, las bondades de su enseñanza están concebidas como un bien al que toda sociedad moderna debe acceder:

De donde debe inferirse, que mientras no sea general la inclinación, y la enseñanza del diseño en todos los pueblos considerables, no llegarán las artes, y los oficios al punto deseado de perfección y esmero. Los maestros de primeras letras deberían saberle, y enseñarle en la escuela por obligación ${ }^{24}$.

No obstante, hay que puntualizar que el arte del dibujo al que con autoridad apela Campomanes es, ante todo, arte del disegno. Y disegno, en el sentido de que su práctica encierra la posibilidad de combinar dos dimensiones sustanciales para su desarrollo: la dimensión especulativa de las ciencias racionalistas y la concreción práctica de las artes manuales. Esta circunstancia queda mucho mejor explicada en los comentarios que hace nuestro autor a la obra de Juan de Arfe y Villafañe ${ }^{25}$, en la que el término dibujo aparece identificado como grafidia:

Grafidia, que es el dibujo, para diseñar las historias, y cosas que hubiere fabricado el artificio en la imaginación. Como si dijera: que no sólo se ejercita en representar al vivo las cosas naturales; sino también todas las invenciones humanas de las artes; no siendo posible darlas a entender suficientemente con cualquier explicación que sea, sin el auxilio del diseño; ni de fijar un modo constante, y arreglado de ejecutarlas ${ }^{26}$.

Así, el dibujo adquiere un valor revelador de la conciencia creativa. Valor, por otra parte, indispensable para convertir la mera especulación (la idea, siguiendo ciertos preceptos que se hicieron muy presentes en el neoclasicismo europeo $)^{27}$, en una posibilidad «real»; en tanto que ofrece una utilidad práctica de conocimiento aplicado. Es decir, un conocimiento configurable, transmisible

${ }^{23} \quad I d$.

24 Ibid., pág. 24.

25 Se refiere a De varia conmensuración, citado por el propio Campomanes en las notas de su Discurso... (vid. nota 31 de la obra ya antes citada).

26 Ibid., pág. 20.

$27 \quad$ El dibujo se inserta en ese ideario estético ilustrado desde una doble vertiente: el aspecto empírico y el aspecto racional. Aunque, a partir de 1770, en particular en Francia, el aspecto empírico se debilita; siendo cada vez más preponderante el aspecto racional; y produciéndose, cada vez de una manera más palpable, una diferenciación entre un dibujo en función de las artes (pintura, escultura, arquitectura) y un dibujo o disegno en función de las ciencias, y de una variante de esas artes: las «artes aplicadas»; que surgieron precisamente de esa exaltación racional de los oficios artesanos. 
y repetible ${ }^{28}$. De este modo, el conde de Campomanes se convierte en depositario de toda una tradición artística y estética que hunde sus raíces en el Renacimiento italiano y que se caracterizó principalmente por contemplar el arte del dibujo, del disegno, a modo de una «escritura viva» ${ }^{29}$. Es decir, una representación gráfica del mundo en base a un sistema ordenado y reglado que posibilita su «reproducción» en máquinas y artefactos ${ }^{30}$.

Dentro de los diversos planteamientos que impulsan el desarrollo del Discurso sobre la educación popular, encontramos de sumo interés lo que podríamos definir como una impronta de tipo moral. Campomanes no concibe una educación técnica, especializada y racionalista, a la vez que útil socialmente, sin el sustento de la moral. De una moral que no puede ser nada más que católica ${ }^{31}$. En el título III del Discurso ${ }^{32}$, se establecen una serie de preceptos al respecto. Lo primero que llama la atención de este título — y también en el IV como continuador de este- es la asociación que realiza entre moral católica y conocimientos útiles. Así, la moral y los conocimientos útiles están destinados a la mejora de la juventud popular. De manera que todo ello, queda asociado a un comporta-

28 Las posibilidades del grabado, de la estampa que tan útil resulta a las ciencias y las artes del siglo XVIII, deben verse como una ampliación reproductiva en serie de los beneficios del dibujo (vid. Antonio de Pedro Robles, El diseño científico. Siglos XV-XIX, Madrid, Akal, 2000.)

29 «La jurisdicción del dibujo se extiende a todo lo visible, y a lo ideal, para presentar los objetos reales, y las ideas inventadas fielmente a la vista. Este admirable hallazgo de los hombres se llama por algunos escritura viva; y así lo declara muy bien el célebre poeta, pintor don Juan de Jáuregui» (RodRíGuez DE CAmPoMANES, op. cit., pág. 21 (nota 37 del autor).

30 Aquí el ilustrado español enlaza con otra idea preponderante durante este periodo: la de la «imaginación activa», es decir, la imaginación está ligada a la acción; sin un procedimiento operativo, sin una técnica con la que realizar las imágenes, es imposible establecer la comunicación y sin comunicación no existe ningún valor. Es por tanto, la imaginación de lo posible, de algo que se puede hacer. De lo contrario, se cae en una imaginación ociosa y arbitraria (en relación con estas ideas, vid. Giulio Carlo Argan, «El valor de la "figura" en la pintura neoclásica», en VV.AA., Arte, Arquitectura y estética en el siglo XVIII, Madrid, Akal, 1987, págs. 71-85).

31 La idea de los ilustrados españoles como anticlericales y anticatólicos es una vieja tesis defendida, entre otros, por Marcelino Menéndez Pelayo (vid. nota 6). Afortunadamente esta idea va perdiendo fuerza y las interpretaciones actuales se acercan a definir la posición de hombres como Campomanes, a lo que podíamos definir como un «catolicismo crítico»; muy alejado, eso sí, del catolicismo de corte popular barroco que alimenta la superstición española. Para estos asuntos, vid. Antonio Mestre, «La actitud religiosa de los católicos ilustrados», en Agustín Guimera (ed.), El reformismo borbónico, Madrid, Alianza Editorial, 1996, págs. 147-163. Para el caso concreto de Campomanes, puede consultarse Alfredo MarTínEZ AlBiach, «Campomanes, un católico ilustrado», en Revista Burgense, núm. 35 (1994), págs. 219-248.

32 Vid. «De los conocimientos cristianos, morales, y útiles, en que conviene instruir la juventud, dedicada a los oficios, y a las artes», en Pedro Rodríguez de Campomanes, op. cit., págs. 25-34. 
miento «honrado y decente» que permitirá que los artesanos fuesen vistos, a los ojos de una «nación llena de pundonor» ${ }^{33}$ como individuos «apreciados y bien quistos» ${ }^{34}$.

Para Campomanes no es posible, en el contexto de la España del momento, hablar de moral más que en el contexto de la religión católica; es decir, del tipo de moral que se insertaba en la sociedad desde la familia, las propias estructuras del trabajo artesanal y era divulgada por maestros y párrocos. Obligados, estos últimos, a «dar esta enseñanza, y a celar en que nadie sea flojo en tomarla, haciendo exámenes, y eligiendo para todos continuas y prudentes medidas» ${ }^{35}$.

Pero lo que más llama nuestra atención de lo referido al respecto por Campomanes, es el hecho de que en asociación con la justa práctica de esta moral católica, se encuentran aspectos como el aseo y la decencia en el vestir; los bruscos y toscos modales; las propias indumentarias de los maestros y aprendices; los vicios de la bebida y el naipe; y las diversiones fuera de medida y hora $^{36}$ :

El desaliño actual de muchos de esta clase honrada de vecinos, tiene su origen en la mala crianza, que se les da a los padres y madres; descuidando de todo punto su aseo; rasgando ellos sus vestidos con las luchas, y otros juegos violentos en que se entretienen, y son poco convenientes a los racionales [...].

Puede atribuirse a este abandono de la decencia general, parte del menosprecio de los artesanos; porque a la verdad su poca limpieza los suele confundir con los mendigos, o vagos ${ }^{37}$.

33 Ibid., pág. 31.

34 Pedro Rodríguez de Campomanes, op. cit., pág. 25.

35 Id. Campomanes no debe incluirse en el grupo de los llamados «deístas españoles» (los Moratín, los Iriarte, Trigueros, Samaniego), defensores de una autonomía moral basada en la ética racional. Por el contrario, Campomanes está en la línea de Mayans, Jovellanos, Cañuelo, caracterizados por una moral católica de la que está ausente la superstición y la supresión de los abusos.

36 Asimismo, Campomanes se refiere a cómo entre los oficiales, maestros y aprendices de los distintos gremios y oficios se producen constantes situaciones de enfrentamiento y degradación verbal y física, por razones de una falsa superioridad entre unas y otras actividades: «[...] es reprensible crianza de los maestros o de padres, apoyarles o tolerarles las pullas y burlas, con que maltratan los de unos oficios a otros; añadiendo otros bajos apodos, y chanzas de escarnio y mofa» (ibid., pág. 31).

La abolición de estas prácticas, considera Campomanes, era necesario no sólo por creerlas injustas e injustificadas, sino por estar condenadas por la ley. Situaciones como estas provocaban que la sociedad siguiese manteniendo su desprecio hacia las actividades manuales, lo que significaba, a todas luces, un alto perjuicio para la buena marcha de la nación: «En una nación llena de pundonor como la nuestra, causa gran daño esta especie de preocupaciones, difundidas contra varias artes y oficios, porque retraen las gentes honradas de ejercitarlos, y otros de continuar en los mismos, que ejercieron sus padres» (cursivas nuestras) (id.).

37 Ibid., págs. 25-26. 
Lo que conlleva a que la expresión de esta moral católica no sólo debe quedar restringida al ámbito de lo privado, sino, por el contrario, debe de formar parte de la representación pública. Y es precisamente en el espacio público, donde el nuevo comportamiento de los obreros y campesinos será juzgado y sancionado como correcto o incorrecto.

Con respecto a las costumbres, el pensador asturiano señala que estas pueden ser un freno o un motor del desarrollo de una nación:

Las costumbres tienen tanto poder, como las leyes, en todos los pueblos. El modo de que las gentes sean honradas, consiste en difundirles costumbres virtuosas, y persuadirles de la ventaja que les producirán. Esta persuasión se ha de infundir desde la niñez en las casas, en la escuela, por los maestros de las artes. El ejemplo de los mayores ha de confirmar a los niños en que sus superiores tienen por bueno lo mismo que recomiendan ${ }^{38}$.

Es obvio, y así lo deja explícito en su Discurso sobre la educación popular, que en la España del dieciocho existen prejuicios en relación con las labores manuales y artesanales, y que los practicantes de estas actividades — vitales para el progreso de la nación- suelen ser vistos con desprecio. Prejuicios que forman parte de una tradición equivocada que hay que desterrar. Pero para que este destierro sea un hecho, es necesario que, a su vez, las viejas conductas de los artesanos, los obreros y los campesinos sean reemplazadas por otras nuevas:

Puede sobre esta distinción darse a las costumbres un lugar preeminente en la dirección de los artesanos, y de las demás clases. Todo el deshonor, que hasta ahora tan injustamente se ha prodigado sobre los oficios; convendría aplicarle a los vicios de los artesanos ${ }^{39}$.

Vicios como el juego, la bebida, las peleas, la mala indumentaria, en nada contribuyen a la recuperación de la estima social. Campomanes está convencido de que para que una nueva legitimidad del trabajo artesanal se dé en el seno de la sociedad de su tiempo, es necesario que las clases populares inicien la renovación de sus costumbres. En primer lugar, por medio de una educación adecuada, destinada principalmente a sus hijos. Y, en segundo lugar, persiguiendo y sancionando todos aquellos vicios que les impiden progresar:
$38 \quad I d$.
$39 \quad I d$. 
Las leyes obran, prohibiendo y castigando. [...].La compasión suele debilitar el rigor de la ley, y el que peca sin testigos que le delaten se cree libre. [...]. No sucede así entre las gentes bien criadas: aborrecen de corazón los delitos o las acciones indecentes. Por no caer en mengua, se abstienen de cometerlas; siguiendo el ejemplo y la costumbre de obrar; que la educación popular encarga, recomienda generalmente ${ }^{40}$.

Si las leyes impulsadas por ese nuevo espíritu renovador no logran su pronto objetivo, es porque las costumbres tienen tanto poder como las leyes ${ }^{41}$. Y, en ese caso, desde la «reconversión» de las costumbres es desde donde hay que atacar el problema del atraso del pueblo español.

En este sentido, en la manera de que los artesanos, los practicantes de los oficios considerados «más viles», sean capaces de presentarse y representarse públicamente bajo una «nueva apariencia», reflejo de un nuevo comportamiento «socialmente correcto», es, en esa medida, que el resto de la sociedad propenderá a legitimar sus tareas. En palabras llanas: la responsabilidad en todo caso es siempre de los artesanos, de los obreros y de los campesinos.

Para que esto se cumpla el Estado ofrece los medios: la educación y las leyes. La educación será el gran instrumento para el convencimiento, propiciando lo que llamaríamos la «domesticación» de su «pensamiento salvaje». En este sentido, Campomanes actúa como un «tecnólogo social», amparado en una utopía de influencia rusoniana que tiene por finalidad tratar de que el individuo se comporte al dictado de una nueva conducta social.

Pero todo cambio como el que propone Campomanes es ante todo un cambio decidido e implementado desde la verticalidad del poder. Un cambio que en ningún momento ha previsto el consenso con los directamente implicados; que no ha sido el fruto de una necesidad manifestada por ellos. En este sentido, Campomanes lejos de considerar y pensar un orden, una estructura y un funcionamiento social en función de las clases populares, diseña un plan de renovación de la conducta social para las clases populares, de acuerdo con los principios del Antiguo Régimen «y que es, a secas, el único régimen y la única perspectiva de la sociedad vigente y futura ${ }^{42}$.

\footnotetext{
$40 \quad$ Ibid., pág. 27.

${ }^{41} \quad I d$.

42 Pablo F. LunA, op. cit., pág. 6.
} 
La fe que los ilustrados tienen en la educación en manos de un estado autoritario, protector y patriarcal, es equiparable a la confianza que tienen en la niñez y la juventud. La niñez es, para pensadores como Campomanes, el momento ideal de la edad del hombre en la que es posible insertar aquellos principios universales que los convertirían en «seres de bien, útiles y honrados». Todo su discurso está plagado de esta referencia a la niñez y a la juventud como elementos de máximo optimismo social ${ }^{43}$. En los jóvenes, consideraba el conde, sería posible inculcar la instrucción necesaria que el progreso del Estado reclamaba.

No ocurre lo mismo en el caso de los adultos. Con ellos Campomanes es menos indulgente y también menos optimista. Las leyes, por lo general, se ven obligadas a actuar para controlar sus vicios y tropelías. En ellos, la educación no puede ejercer su beneficioso discurso de autocontrol. Y es sobre ellos, y no sobre los jóvenes y los niños, que se debe ejercitar todo el peso de las leyes: «De donde se sigue, que los adultos ya no pueden mejorar sus costumbres sin el rigor de las leyes; y que sólo los niños tienen la dicha de poder ser buenos con la educación y ejemplo sin la necesidad de que los castigos los aflijan, e infamen ${ }^{44}$.

La ociosidad es, sin duda, el mal más extendido entre el pueblo español. El ocio es «tiempo robado» al trabajo; y este constituye el principal factor de progreso de la sociedad y del individuo:

No hay otro baluarte en lo humano, para librar al pueblo de tan peligrosos escollos, que ocuparle en los días de trabajo, a fin de que apetezca a sus horas el sueño y descanso; acostumbrarle a cumplir en los días de precepto con las obligaciones, que prescribe la Iglesia; y disponer en los tiempos libres las diversiones populares, que agilicen las fuerzas del cuerpo, las cuales por la publicidad misma, y el orden que debe establecer el Magistrado, no pueden degenerar en abuso o corruptela. Estos juegos públicos piden reglas y horas, estando cerrados en el día de trabajo $0^{45}$.

Si bien en la Europa de finales del siglo XVIII se produce una cierta revalorización del tiempo libre y de lo lúdico, esta situación está en función de las distintas clases sociales. Así, en una sociedad como la española en la que el

43 Otros ilustrados españoles como Jovellanos, también harán una exaltación de la infancia como un estado ideal para la inculcación de los nuevos ideales (vid. en especial la obra de este autor Memoria sobre la educación pública o tratado práctico de la enseñanza, 1802).

44 Rodríguez de Campomanes, op. cit., pág. 27.

45 Ibid., pág. 29. 
trabajo manual es asumido, al mismo tiempo, como una «maldición divina» y como un factor de desarrollo económico, la ociosidad es vista como uno de los problemas de mayor importancia. Las observaciones de Campomanes sobre el ocio de los artesanos, sobre sus características y regulación, están claramente destinadas a ejercer un control sobre el principio del «libre albedrío»; es decir, de la posibilidad de escogencia del uso y disfrute del tiempo de descanso. De manera que, el qué y el cómo se hace uso de este tiempo, no es una decisión personal y menos aún para las clases populares, cuya misión principal es la producción de bienes y el sustento de las otras clases: el tiempo libre, el ocio, son cuestiones que incumben al Estado, que será quien lo regulará y, en su caso, lo sancionará.

Pero también las clases populares deben divertirse: «No debe la juventud, que se dedica a las artes y oficios, carecer de diversiones; porque los recreos inocentes son una parte esencial de la policía y buen gobierno» ${ }^{46}$.

Tiempo de diversión que se debe dar en el tiempo de descanso, no del trabajo. Ya que este, el trabajo, no se contempla como un instrumento de realización individual, sino, por el contrario, como un necesario esfuerzo que el individuo debe ofrecer al sustento común. De manera que la diversión es una necesidad impuesta por la propia condición «alienada» que tiene ese trabajo. Un tiempo de descanso prudente y organizado que entronca con el ideario moral del catolicismo: «Es necesario absolutamente, que la gente moza se divierta, y tenga días destinados al descanso de sus fatigas ordinarias, y penosas de todo el resto de la semana. Lo contrario sería exponerla a hostigarse con el trabajo, y a aborrecerle» ${ }^{47}$.

Por otra parte, ese tiempo de descanso, de diversión, también puede constituir un nuevo instrumento de aprendizaje: la posibilidad de desarrollar ciertas cualidades físicas tan necesarias para el desempeño de determinados oficios. Así, la práctica de determinados juegos populares (el «juego de la pelota, los bolos, de bochas, de truco, tiro de barra o esgrima» $\left.{ }^{48}\right)$, son actividades recomendadas para que los jóvenes ejerciten «las fuerzas corporales, y son útiles a la salud, e inocentes en sí mismos» ${ }^{49}$. Lo mismo se podía decir de otras diversiones como «el baile público en semejantes días, que con mucha decencia se estila de tiempo inmemorial en algunas provincias septentrionales de España» ${ }^{50}$. Como finalmente afirma Campomanes:

\footnotetext{
Ibid., pág. 28.

7 Id.

$I d$.

Id.

$I d$.
} 
Las diversiones comunes de esta clase son de gran utilidad, cuando no se tienen en días de trabajo; y se observan en ellas orden y compostura. Recrean honestamente el ánimo; acrecientan las fuerzas corporales de la juventud, y acostumbran el pueblo a un trato recíproco y decente en sus concursos.

Los que faltan a ellos, deben ser notados: porque no es en estas concurrencias generales, donde se estragan las costumbres; y sí en los parajes ocultos y apartados del trato común; cuya separación deben estorbar cuidadosamente los padres y maestros, porque allí, y en las tabernas es el paraje, donde se empiezan a corromper y estragar los jóvenes ${ }^{51}$.

Las «sanas diversiones», impulsadas por Campomanes, también actúan como instrumento coercitivo, alejando a los jóvenes artesanos del vicio al que suelen ser tan propensos: «Les hará estimables, y dignos del aprecio común de las demás clases, viendo sus modales civiles y atentos, de que ahora inculpablemente carecen algunos» ${ }^{52}$.

Pero no conforme con ello, Campomanes quisiera que los artesanos españoles se fijasen en los aplicados trabajadores alemanes y su abnegado sentido del deber:

Algunos ratos del día de fiesta, que son los que únicamente tienen libres, en vez de diversión, los aplican los artesanos en Alemania, a perfeccionarse en el dibujo. De esta suerte han adelantado mucho los oficios, en la facilidad y corrección de sus obras. Tanto es el ahínco con el que aprovechan su tiempo sin desperdicio alguno; y así salen los alemanes excelentes obreros ${ }^{53}$.

Pero para bien o para mal —debía pensar nuestro autor- España no era Alemania ${ }^{54}$. Y en España la «fiesta» era una tradición asentada con la que había

$51 \quad$ Ibid., pág. 29.

$52 \quad I d$.

$53 \quad I d$.

54 Es obvio que no queremos aquí caer en la trampa, tantas veces establecida a lo largo de la historiografía sobre la Ilustración española, de que los ilustrados eran catastrofistas. Muy por el contrario, abogamos - y así se desprende de la lectura de este texto, como también de muchos otros de autores contemporáneos a Campomanes- que los pensadores de la Ilustración española tenían una fe inquebrantable en las potencialidades naturales de sus connacionales, y que el atraso imperante de España era producto del degenerado carácter español, sino de unas prácticas y unas costumbres equivocadas, ancladas en un cierto ensimismamiento que no les permite abrirse a las corrientes universales, es decir, al resto de Europa.

No obstante, tampoco podemos caer en un falso optimismo. Es necesario tener presente que esos mismos ilustrados eran conscientes del peso negativo de la tradición, de los lastres y rémoras de la historia española y, en particular, a Campomanes, hombre de indudable saber histórico, no le dolían prendas en criticar con dureza, incluso con acritud, ciertos pasajes históricos de la historia de la monarquía española, en especial de 
que contar. Por eso, era necesario que el Estado pusiese en práctica todo su poder policial, religioso, familiar y educativo, para que el amor al trabajo fuese asumido como una necesidad, como un nuevo referente de la cultura popular:

La ociosidad es la que con preferencia debe tener impresa una nota de deshonra; cuya máxima conviene mucho, que los padres de familia repitan a sus hijos, o a sus pupilos, aunque no sean artesanos; y que los párrocos desimpresionen a sus feligreses de unas opiniones, contrarias a la felicidad pública; y que sin un esfuerzo común dificultosamente podrán disiparse ya.

Después de los padres y párrocos son las justicias en sus casos, y con sus exhortaciones, los únicos que podrán esperar unos resabios que no se fundan en la naturaleza, ni en la razón. [...]

La educación, o por mejor decir el abandono, con que se cría a los artesanos, ha firmado este sistema común, contrario a las artes. Ahora no basta que la misma educación deshaga tales yerros, si no concurre al mismo objeto el todo de la nación: imbuyendo a las gentes en ideas más favorables a los oficios, y a su bien merecida estimación ${ }^{55}$.

Viene a colación recordar aquí los versos altruistas de otro ilustrado asturiano ilustre, Jovellanos:

Una razón común, un solo y mutuo amor los atarán con dulce lazo; una sola moral, un culto solo, en santa unión y caridad fundados, el nudo estrecharán, y en un solo himno, del Austro a los Triones resonando, la voz del hombre llevará hasta el cielo la adoración del universo, a la alta fuente de amor, al solo Autor de todo ${ }^{56}$.

Un sentido del bien que se ancla, por excelencia, en la conquista de la «felicidad pública».

\section{V}

En el apartado IV del Discurso sobre la educación popular, Pedro Rodríguez de Campomanes plantea la necesidad de que la juventud dedicada a las artes y

la dinastía de los Austrias, dinastía en la que los imperativos perjudicaron los intereses nacionales (vid. Pedro Rodríguez de Campomanes, Discurso sobre el fomento de la industria popular, Madrid, 1774).

55 Ibid., págs. 31-32.

56 Estos versos son de Gaspar Melchor de Jovellanos (1744-1811) (citado en Francisco FlECHA Andrés, Antropología y educación en el pensamiento y la obra de Jovellanos, León, Universidad de León, 1989, pág. 90). 
oficios «se apliquen a los primeros rudimentos de leer y escribir» ${ }^{57}$. Esta medida, impuesta muy a pesar del criterio de quienes piensan que la lectura y la escritura está reñida con el ejercicio de los trabajos manuales, traerá enormes beneficios a la nación española: «De no aplicar los niños entonces a leer y escribir, resulta, que estén ociosos en aquella tierna edad, y que se impresionan de especies, de ideas que les perjudican demasiado, cuando llegan a ser adultos ${ }^{58}$.

Es vital para los ilustrados que en su proyecto de regeneración de las costumbres, el Estado moderno y desarrollado ejerza un control de una educación básica; es decir, que se establezcan las bases prioritarias de un aprendizaje básico común a todas las personas sin distinción de clase ${ }^{59}$.

Esta educación básica, contemplada como primaria, constaría principalmente de leer y escribir; además de la enseñanza del catecismo cristiano, los principios de matemática, la educación física, y, por supuesto, el dibujo ${ }^{60}$. Hay razones de gran peso, según Campomanes, para que los jóvenes oficiales sepan leer y escribir, y no sólo aquellos planteamientos que forman parte del ideario ilustrado a nivel mundial ${ }^{61}$. Una juventud artesana conocedora de los rudimentos del idioma, de las reglas básicas de la aritmética y de los comportamientos sociales adecuados, es, ante todo, una juventud útil:

57 Campomanes, Discurso..., op. cit., pág. 35.

58 Id. (cursivas nuestras).

59 Jovellanos, Meléndez Valdés y Cabarrús, por citar tres nombres importantes de la ilustración española, se manifiestan en este sentido de conseguir una educación básica, sin distinción de clases. Una educación que conformaría de hecho las estructuras de una enseñanza nacional uniforme. Cabarrús planteaba que esta educación básica debía ir desde los seis años hasta los diez. A partir de esa edad se orientaría a los niños según su vocación, pero también va tendiendo a las necesidades de la sociedad. De este modo, proponía reducir el número de ingresos en el sacerdocio, en la milicia, la jurisprudencia, en todas aquellas actividades que él consideraba «parasitarias». Aumentando, por el contrario, el número de agricultores, artesanos, industriales y comerciantes. Y, por descontado, debían desaparecer las universidades, a las que Cabarrús denominaba «cloacas de la humanidad» (vid. Jean SARrailh, La España Ilustrada de la segunda mitad del siglo XVIII, Madrid, Fondo de Cultura Económica, 1985).

60 La enseñanza del dibujo no sólo era impulsada por Campomanes, sino que otros ilustrados como Jovellanos o el mismo ministro de Marina, Antonio Valdés, lo consideraban de enorme utilidad. En el Instituto de Gijón diseñado por Jovellanos, el dibujo pasó a ser materia de obligado estudio; y se enseñaba en la clase misma de matemáticas (Jean SARRAILH, op. cit., págs. 221-222).

61 Estas ideas formarán parte ya del ideario educativo moderno. La preocupación de la monarquía española por la enseñanza de la escritura y la lectura del castellano constituyó una acción continuada desde tiempos anteriores a los planteamientos de los Borbones. No obstante, con el reformismo esta acción se intensificó y se convirtió en una «verdadera cruzada» que trascendió al territorio peninsular y llevándose a cabo también en América, donde fue aplicada a amplias capas de la sociedad incluida la de los indios. El republicanismo americano del siglo XIX también incorporará a sus programas educativos la batalla contra el analfabetismo, desarrollando programas basándose en el método lancasteriano, previamente probados en Europa, que no siempre dieron los resultados esperados. El siglo XIX americano, como en tantos otros aspectos, fue un continuador de los planteamientos ilustrados en materia de educación (para el caso de México, vid. Dorothy Tanck Estrada, 1977: La educación ilustrada 1786-1836. Educación primaria en la Ciudad de México, México, El Colegio de México). 
Confieso me holgaría poderles dispensar de esta tarea. Si lo creyese incompatible con la industria popular, o superflua, sería el primero a prohibirla. Por no saber estos rudimentos de las primeras letras los artesanos, se llenan nuestras manufacturas de plumistas, que les suplan en esta parte, para la cuenta y razón. [...] Ellos son otros tantos ociosos, que viven a costa de la industria ajena: llenos no pocas veces de presunción, con ruina inminente de las artes; a cuyos profesores desprecian altamente por lo común, y los miran en una clase muy inferior a la suya, y aún suelen quererles dar reglas en su oficio, que ignora ${ }^{62}$.

Pero la lógica pragmática de nuestro autor, choca, una vez más, con unas tradiciones y costumbres que promueven trabajos estériles y poco productivos. En este sentido, ve como innecesarias profesiones como las desarrolladas por los popularmente denominados plumistas, quienes formarían parte de esos tantos trabajos «ociosos» que impiden el progreso. En tal sentido precisa: «Llamo ocio a toda ocupación, que puede excusarse, con dar mejor crianza a la juventud artesana, y que no rinde provecho inmediato, antes agrava con salarios las fábricas» ${ }^{63}$. En la sociedad vislumbrada por Campomanes toda actividad debe brindar un provecho. El economicismo como teoría del rendimiento de todos aquellos que componen el «cuerpo del Estado», está previsto para todas las instancias de la acción social ${ }^{64}$. En este sentido, se educa para formar ciudadanos útiles, productivos y buenos ciudadanos, respetuosos de la ley y el orden. En una sociedad así, labores como las de los plumistas no tienen cabida: «En una hora puede un artesano de mediana instrucción hacer asientos, liquidaciones, y cuentas que ocupan un número de plumistas, destituidos de la pericia de las manufacturas, dedicando el resto de su tiempo a la fábrica» ${ }^{65}$.

Pero si el factor económico se convierte en el argumento principal para la educación de las clases productivas, esta se completa con el conocimiento de los principios morales: «Por medio de la lectura el aprendiz de un oficio, repasa por

$62 \quad I d$.

63 Ibid., pág. 36.

64 Las ideas de Campomanes son refrendadas por otros ilustrados como Jovellanos. Ambos comparten ese mismo ideal utilitario y economicista de la educación como un bien generador de bienes, de las riquezas necesarias de las naciones. En Jovellanos, el desarrollo de establecimientos de «enseñanzas útiles» está plenamente establecido en su Informe sobre la Ley Agraria del año 1794, en la que está presente esta necesidad que sienten los ilustrados españoles por derribar el muro de los que estudian y trabajan, entre la teoría y la práctica, entre la investigación y la acción. Para Jovellanos, como también para Campomanes, el papel del intelectual consiste, ante todo, en investigar verdades útiles y ponerlas al alcance de los analfabetos y desterrar los prejuicios que impiden el progreso de las «artes necesarias» (vid. Ángeles Galino CarRILlo, «Gaspar de Jovellanos (1744-1811)», en Perspectiva. Revista trimestral de educación comparada, Unesco, vol. XXIII, núm. 3-4 (1993), págs. 808-821).

65 Ibid., pág. 36. 
sí mismo el catecismo de la doctrina cristiana» ${ }^{66}$. Además, esta tarea contribuye a su autoformación: "[...] los discursos, que tratan del fenómeno de la industria, y de la educación popular, para proceder con sistema constante, y adoptar los principios acomodados a sus obligaciones ${ }^{67}$.

Por último, los trabajadores serán conscientes de sus obligaciones gremiales, «de las ordenanzas, y policía de su gremio y oficio, para dedicarse a observarlas, y entenderlas con propiedad; o para advertir lo que convenga, y se le alcance con el tiempo» ${ }^{68}$. Estamos pues, ante una alfabetización en función de un mejor rendimiento:

Es de creer también, que los artistas de más sobresaliente ingenio, educados sobre este plan, encuentren nuevas combinaciones, facilidades, y descubrimientos en su oficio; y que le sepan enseñar más bien: pues que le han aprendido por reglas, y con mejor educación ${ }^{69}$.

Pero toda acción lleva implícita su posibilidad de desviarse de los objetivos trazados. Por ello, Campomanes no quiere dejar «cabos sueltos» y que la lectura pase del «beneficio» al «vicio». Para evitar esto, es necesario que un instrumento tan poderoso, en manos de las clases populares, sea restringido a lecturas de carácter profesional o doctrinal:

No deberán leerse en las escuelas romances de ajusticiados, porque producen en los rudos semilla de delinquir, y de hacerse balandrones, pintando como actos gloriosos las muertes, robos, y otros delitos, que guiaron al suplicio. El mismo daño traen los romances de los doce-pares ${ }^{70}$, y otras leyendas vanas o caprichosas, que corren en nuestro idioma, aunque el Consejo no permite su reimpresión ${ }^{71}$.

Nuevamente, no hay posibilidad, en este aprendizaje, para el «ocio creativo». La lectura es un instrumento exclusivo de la formación:

Establecida la educación cristiana, civil y directiva en la juventud, que se dedica a los oficios, no serán necesarias a las fábricas con el tiempo las oficinas, en que ahora se ocupa inútilmente un gran número de personas, que en tal caso podrán

\footnotetext{
$66 \quad I d$.

$67 \quad I d$.

$68 \quad I d$.

$69 \quad I d$.

70 Este romance de los «Doce Pares» aparece mencionado ya en El Quijote, y se refiere a los Doce Pares de Francia.

71 Pedro Rodríguez de Campomanes, Discurso, op. cit., pág. 36 (la nota 79 es nuestra).
} 
ser ellas mismas fabricantes; y miembros onerosos al común, se hacen ciudadanos útiles y provechosos ${ }^{72}$.

\section{VI}

En su particular campaña contra la ociosidad, los ilustrados españoles no hacen distinciones de género. En este sentido, las mujeres de las clases populares también van a ser objetivo de la reforma educativa. Todo ello bajo el objetivo general de hacer del pueblo «el uso más ventajoso, para que todo esté ocupado; y cuantas personas le compongan, ganen honestamente de qué vivir» ${ }^{73}$. Si bien, la ociosidad había arraigado en la mujer española desde antiguo, esta situación no siempre había sido así. Y era necesario remontarse en la historia para conocer los orígenes auténticos de su condición; que, por otra parte, todavía podía verse reflejada en muchas regiones del norte español como Galicia, Asturias, la Montaña (actual Santander), Vizcaya y Guipúzcoa para comprobar cómo las mujeres seguían practicando faenas que compartían con los hombres, como la pesca o la agricultura. Además, ejercían oficios de tenderas y panaderas. Situación que no era frecuente en otras regiones de España, donde la ociosidad había arraigado a causa de la larga presencia de los árabes:

Las antiguas españolas, hasta el siglo octavo de la era cristiana, todas vivían ocupadas, y es resabio derivado de los árabes la indiferencia actual. La práctica de algunas provincias, no debe prevalecer a la general laboriosidad de nuestros mayores. [...].

Las malas costumbres no se defienden bien, por ser antiguas; antes prueban descuido en aquellos, que las han introducido, o tolerado.

Esto se entiende, aun omitiendo la solidísima solución de que nuestra antigüedad española tenía costumbres activas, y del todo opuestas al abandono, que se intentan reformar. Su época empezó desde el siglo octavo, en que los árabes invadieron, y ocuparon gran parte de la España, en que permanecieron hasta el año 1492 de Cristo.

Esta larga mansión de 700 años ha podido influir algunas costumbres. La reina Católica reprendió en las mujeres de Córdova la ociosidad; y nadie que ame el estado y la felicidad de las mujeres, podrá aprobar, que vivan descuidadas, y llenas de una pobreza y desnudez voluntarias ${ }^{74}$.

$72 \quad$ Ibid., pág. 38.

3 Pedro Rodríguez de Campomanes, Discurso, op. cit., pág. 98.

$74 \quad$ Id. 
Ante la gravedad del problema, urgía implementar medidas correctoras. Había que hallar el modo de remediar «una continua perdida de la industria, por la tolerancia de las costumbres, contrarias al sistema político, que conviene a la nación» ${ }^{75}$. Era necesario reestructurar las ordenanzas de gremios que se habían «contaminado» de esas prácticas discriminatorias que convertían a las mujeres en seres ociosos:

El modo más seguro, de prepararles ocupación útil [se refiere a las mujeres], es abolir las ordenanzas de muchos gremios superfluos, y perjudiciales, que han dedicado hombres a las cosas, para que no eran necesarios, y las han prohibido a las mujeres, que no pueden ser gremiales ${ }^{76}$.

El problema del trabajo de las mujeres no estaba relacionado con sus capacidades para ejercer o no determinadas tareas, discusión que Campomanes entendía ya superada ${ }^{77}$, sino en el hecho de que España, por razones «foráneas ${ }^{78}$, había desatendido socialmente a sus mujeres. Se hacía evidente el impulso de una educación que animase su espíritu laboral y de servicio social. Además, y esta constituye la razón principal del interés de los ilustrados por insertar laboralmente a la mujer española en la sociedad, el trabajo de las mujeres, en tareas propias de las artes y los oficios, contribuiría decididamente al desarrollo económico de la nación; como así había quedado probado en otras naciones:

En los países, donde la educación y el uso se han acostumbrado a un trabajo más pesado y recio de las mujeres, se puede inferir, que el pueblo es más laborioso, y que ha tenido una educación popular, ventajosa al mismo pueblo, y a la felicidad general del Estado. Las costumbres en semejantes provincias, son más inocentes, y distantes de la pereza y desidia oriental ${ }^{79}$.

Pero la superación de los viejos hábitos sociales, la habitual discriminación laboral de parte de los gremios hacia la mujer, no eran cosas fáciles de

75 Id.

76 Id. (los paréntesis son nuestros).

77 Para Campomanes, las mujeres tienen las mismas capacidades intelectuales que los hombres, y esta disputa parece necia, como ya lo había probado Feijoo, a quien el pensador asturiano cita en su Discurso (vid. nota 78 del texto).

78 Campomanes mantiene enormes recelos ante las aportaciones históricas del componente árabe. Sus afirmaciones, en este sentido lo acercan a una visión de la historia española determinado por la exclusión, y en la que tan sólo el referente cristiano se impone como válido y positivo.

79 Ibid., pág. 101. 
superar. No era «obra de un día, deshacer los yerros políticos» ${ }^{80}$. Porque, como bien afirmaba el ilustrado asturiano, «todo depende de la educación» ${ }^{81}$. Por ello, lo primero que hay que enseñar es a leer y escribir. Y a este fin, deben incorporarse no sólo las madres, quienes serán las primeras en facilitar este ejemplo, sino el establecimiento de maestras de «cuenta pública» con la intención de fijar esa educación sobre «cimientos sólidos»: «Donde haya fondos de propios, es cosa prudente asignar un salario, competente a estas maestras; y que las madres y los párrocos cuiden de que las niñas no falten a esta enseñanza» ${ }^{82}$.

La educación de las niñas es una prioridad de las autoridades públicas pero necesita del apoyo de los padres: «Pues en las personas de estas niñas, serían inútiles las leyes coactivas, si los padres de familia no quedan responsables al cumplimiento» ${ }^{83}$.

Por otra parte, la educación de las mujeres no sólo debe estar restringida a las hijas de las clases populares. Es necesario que también se aplique a las hijas de los nobles, de los ricos, «sin perjuicio de la labor». Ya que ellas, un día serán madres de familia y constituirán un «ejemplo de imitación» ${ }^{84}$.

Asimismo, los estamentos religiosos tienen un especial papel que jugar en esta estimulación de la educación y el trabajo femenino:

Encargadas de la enseñanza de las niñas acomodadas, y reglándose la economía en el gasto, de manera que no hubiese abuso, exceso, ni granjería contra los padres de familias, harán gran provecho los conventos de monjas al Reino; y contribuirán eficazmente a la educación del sexo, de que ahora hay una falta, casi general ${ }^{85}$.

Lo mismo que el clero:

Los párrocos, y todo el clero, deberían concurrir a estos fines; procurando hacer las convenientes exhortaciones a todas las clases del pueblo, para introducir, y persuadir la utilidad de la aplicación de las mujeres a la labor, según sus diferentes estados: unas para emplear útilmente su tiempo, y otras para mantenerse con recato y honestidad, a costa de sus tareas $\operatorname{caseras}^{86}$.

\footnotetext{
Ibid., pág. 102.

Id.

Id.

$I d$.

Ibid., pág. 103.

Id.

$I d$.
} 
Los oficios y artes a las que se pueden dedicar las mujeres son muchas, según Campomanes. En su Discurso establece una amplia lista de actividades, yendo desde los trabajos textiles; pasando por la ocupación en todo lo que atañe a los adornos, encajes, medias, calcetas, etcétera, hasta oficios de panaderas, tenderas, confiteras y pasteleras. Es decir, toda una serie de ocupaciones dignas, destinada al aumento de la «riqueza nacional» y el destierro «del sexo en lo posible toda ociosidad» ${ }^{87}$.

La obra de Campomanes recoge muy bien los lineamientos fundamentales del ideario ilustrado español en relación con la educación; en especial, con respecto a la educación de las clases productoras. Esta es vista como un instrumento de indudable valor y beneficio social y económico. Su pensamiento educativo se mueve dentro de ese escenario movedizo de la política borbónica, representativo de lo que el historiador inglés John Lynch ha denominado «una curiosa mezcla de gusto por la reforma y tendencia a la tradición ${ }^{88}$. Su Discurso sobre la educación popular de los artesanos y su fomento, constituyó un intento que no puede considerarse tan sólo como un plan de educación especializada destinado a un amplio sector de la población, sino que debe ser entendido como un proyecto cuya máxima finalidad era establecer una serie de medidas educativas para la reorganización de la sociedad tradicional. El liberalismo conservador de Campomanes sólo persigue sujetar y reorganizar las bases populares y sus modos de producción en función de brindar una mayor fortaleza al Estado monárquico absolutista; en absoluto ha pretendido su superación o destrucción. Nada sustancial en el cuerpo de la sociedad monárquica española estaba en peligro, con la aplicación de las líneas maestras desarrolladas en este Discurso. Tan sólo el exceso de los poderes de determinados grupos: los intereses creados de la aristocracia y el clero; y la ociosidad, que como un cáncer carcomía las entrañas y aspiraciones futuras de la nación, podían sentir algún temor.

Al proponer la adaptación del reino a los nuevos tiempos, los ilustrados españoles no hacían otra cosa que imaginar los cambios posibles dentro de un pragmatismo político con el que superar el desfase con Europa. En este sentido, la educación no era un fin en sí mismo: no tenía una finalidad de carácter filantrópico, ni tampoco estaba destinado a la exaltación del carácter individual; sino que estaba concebida como una actividad de utilidad social, un bien común que en manos de un Estado monárquico y absolutista que aspira a obtener el plácet de «estado moderno», lograría superar los desequilibrios económicos que, día a día, debilitan sus estructuras.

87 Ibid., pág. 105.

88 Agustín Guimerá (ed.), El reformismo borbónico, Madrid, Alianza Editorial, 1996, pág. 260. 


\section{Bibliografía}

AlPERs, Steplana, El arte de describir. El arte holandés en el siglo XVII, Madrid, Hermann Brumen, 1987.

Argan, Giulio Carlo, «El valor de la "figura" en la pintura neoclásica», en VV.AA.: Arte, arquitectura y estética en el siglo XVIII, Madrid, Akal, 1987.

Beccaria, Cesare, De los delitos y las penas. Barcelona, Urbis, 1984.

Flecha Andrés, Francisco, Antropología y educación en el pensamiento y la obra de Jovellanos, León, Universidad de León, 1989.

Galino Carrillo, Ángeles, «Gaspar de Jovellanos (1744-1811)», en Perspectiva: revista trimestral de educación comparada, Unesco, vol. XXIII, núm. 3-4, 1993, págs. 808-821.

Jaucourt, «Pueblo», en La Enciclopedia, s. v., Barcelona, Crítica, 1988.

LunA, Pablo F., «El intocable dominio y las reformas de la posesión: Los planteamientos de Campomanes», en Tiempos Modernos. Revista Electrónica de Historia Moderna, Barcelona, 2005, núm. 12, 2 vols., 〈www.tiemposmodernos.org〉.

Lynch, John, La España del siglo XVIII, Barcelona, Crítica, 1999.

Martínez Albiach, Alfredo, «Campomanes, un católico ilustrado», en Revista Burgense, núm. 35, 1994, págs. 219-248.

Menéndez Pelayo, Marcelino, Historia de los heterodoxos españoles. Regalismo y Enciclopedia, México, Editorial Porrúa, 1983.

Mestre, Antonio, «La actitud religiosa de los católicos ilustrados», en Agustín Guimera (ed.): El reformismo borbónico, Madrid, Alianza Editorial, 1996.

Pedro Robles, Antonio de (2000): El diseño científico. Siglos XV-XIX, Madrid, Akal.

Rodríguez de Campomanes, Pedro (1775): Discurso sobre la educación popular de los artesanos y su fomento, edición digital a partir de la edición de Madrid, Imprenta de Antonio Sancha de 1775 y cotejada con la edición crítica de John Reeder (Madrid, Ministerio de Hacienda, 1975).

SARrailh, Jean, La España Ilustrada de la segunda mitad del siglo XVIII, Madrid, Fondo de Cultura Económica, 1985.

Souberroux, Jacques, «La biblioteca de Campomanes: contexto cultural de un ilustrado», en AIH. Actas VII, Instituto Cultural Cervantes, Madrid, 1980.

TAnck Estrada, Dorothy, La educación ilustrada 1786-1836. Educación primaria en la ciudad de México, México, El Colegio de México, 1977.

Vericat, José, «A la búsqueda de la felicidad perdida. La expedición Malaspina o la interrogación sociológica del imperio», en Fermín DEL PINO (coord.): Ciencia y contexto nacional en las expediciones ilustradas a América, Madrid, Consejo Superior de Investigaciones, 1988. 